\title{
Nanoparticles and Public Health
}

\section{Graham Cliff}

Retired from the University of Manchester, School of Materials Science and Materials Engineering, England

zen177374@zen.co.uk

I write this as a materials scientist concerned about the inadequacy of regulation, monitoring, and control of what are known as nanoparticles (NPs). This is not because present particulate legislation is "inadequate" but because it is inadequately policed and does NOT extend to small enough particulates. I have analyzed these very small particles in the analytical electron microscope (AEM) for over thirty-seven years. A graduate student, with whom I worked over thirty years ago, described in her thesis the conclusion that these particles would have "long-range environmental impact." We did not then have the benefit of hindsight.

I do now, however. Moreover, I believe that today we are seeing not just the familiar effects of inhaling particulates, namely respiratory diseases and cardiovascular effects, but we are perhaps also seeing particulates causing DNA disruption [1], aggravation of autoimmune conditions [2], and perhaps even aggravation of dementia [3]. In the UK, the Department for the Environment, Farming, and Rural Affairs (DEFRA) informs me that electron microscopy is not employed in evaluating nanoparticles. Indeed, in the UK, aerosol particulates are only regulated to PM10 (Particulate Matter to $10 \mu \mathrm{m}$ ). The European Union made provision for legislation in 2008 requiring that this should improve to $2.5 \mu \mathrm{m}$ by 2010 . Whilst this legislation is now in place, currently there is no regulation in the UK for particles smaller than PM2.5. According to a document in my possession, here in the UK it is presumed that regulation of "larger particle fractions are controlled, monitored, and reported by process operators, and monitored, reported, and regulated by the Environment Agency. This is likely to provide effective control of nanoparticles." I will not comment on this statement.

Submicron PM1 particles can only be observed in the electron microscope. Light microscopy cannot resolve them. That analytical electron microscopy is employed for asbestos-like "fibrous" material but not nanoparticles is anathema for me. (The atomic force microscope, the AFM, also has been employed in the observation of small particles, but the AFM cannot provide the analytical capabilities of the AEM.)

Apparently nanoparticles are out of sight-and thus out of mind? Certainly, I see no evidence for the application of the "precautionary principle" in the use of NPs. This has been the case for small particles in general for over forty-five years according to the late Dr. Vernon Timbrell, once of the Pneumoconiosis Unit in Penarth, Wales, from whom I was provided with mineral standards to characterize my Cliff-Lorimer k-factors.

The BBC World Service recently discussed the potential for harm from nanoparticles, but, in my personal opinion, it did not reach a conclusion - "the jury is out" seemed to be the main point from my perspective. Dr. Richard Denison of the Environmental Defense Fund, Washington, DC, agreed in this broadcast that the laws presently in place are adequate.

The problem is that submicron particles cannot be adequately monitored without electron microscopy, and electron microcopy is not generally employed for the evaluation of equi-axed environmentally harmful particulates. The electron microscope is used in research institutions, but not for the regulation of nanoparticles. How can this potential problem, for "unforeseen" harm to human health, be resolved before it is too late? There is a clear need to properly research the toxicology of nanoparticles and not presume that they are either all good or all bad. We need to determine the truth. We know the harm of ionizing radiation and chemotoxicology; however, we use both for beneficial purposes in the treatment of cancer. The same approach should be applied to the use of nanoparticles. As we learn more about their potential for good, we should not be ignorant of possible hidden harm they may cause. I believe that the required microscopy on nanoparticles should be to nanometer dimensions.

\section{References}

[1] "Nanoparticles may cause DNA damage across a cellular barrier." Personal communication from Prof. Patrick Case, Bristol University, 2009, http://www.bristol.ac.uk/news/2009/6639.html.

[2] S Bernatsky et al., Environmental Health Perspective 119 (2011), http://www.ehp-digital.com/ ehp/201101?pg=81\#pg81.

[3] Personal communication from Prof. Raymond Agius, University of Manchester, 2010. 

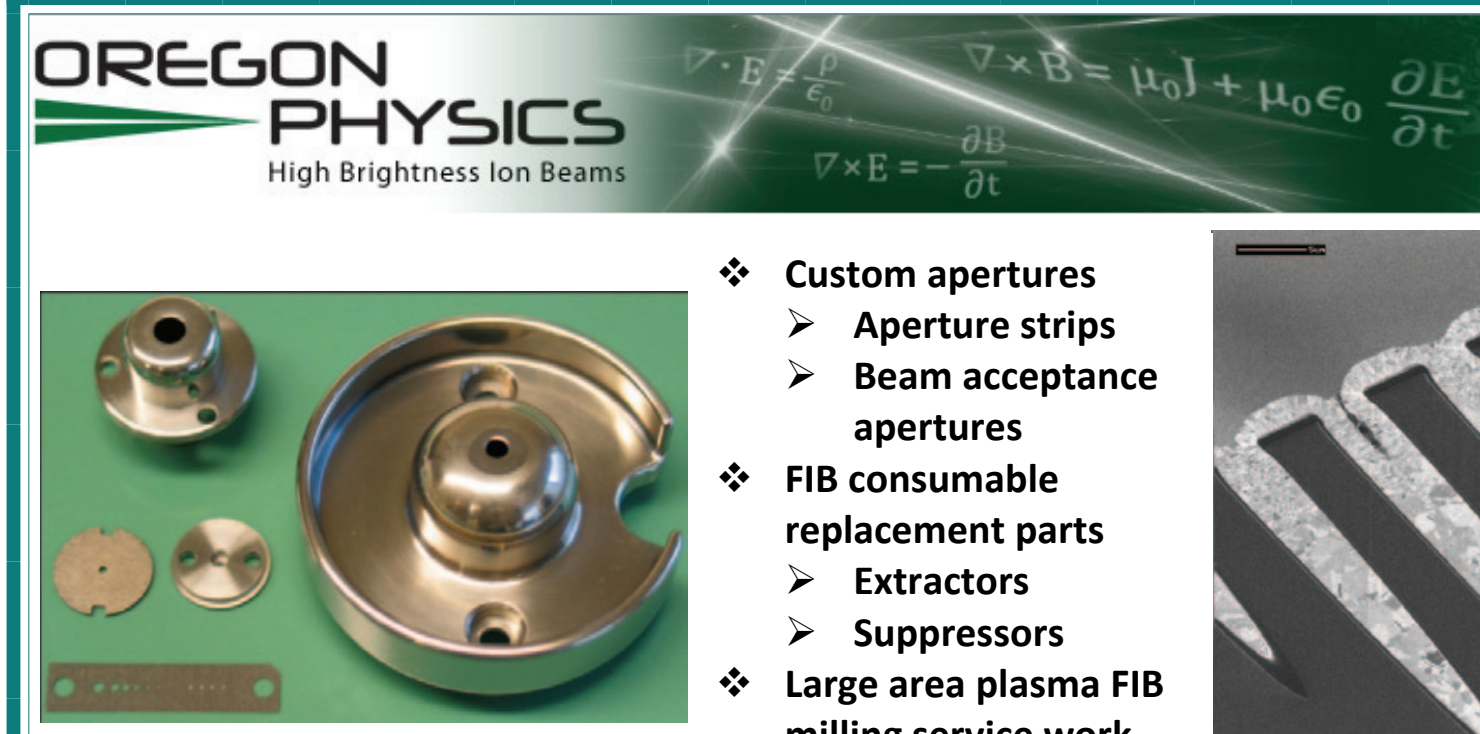
* Custom apertures
$>$ Aperture strips
$>$ Beam acceptance apertures
* FIB consumable replacement parts
$>$ Extractors
$>$ Suppressors
* Large area plasma FIB milling service work

Oregon Physics LLC, 2704 SE $39^{\text {th }}$ Loop, Suite 109

Hillsboro, OR 97123 USA

oplab@oregon-physics.com www.oregon-physics.com

Tel/FAX: +1-503-601-0041

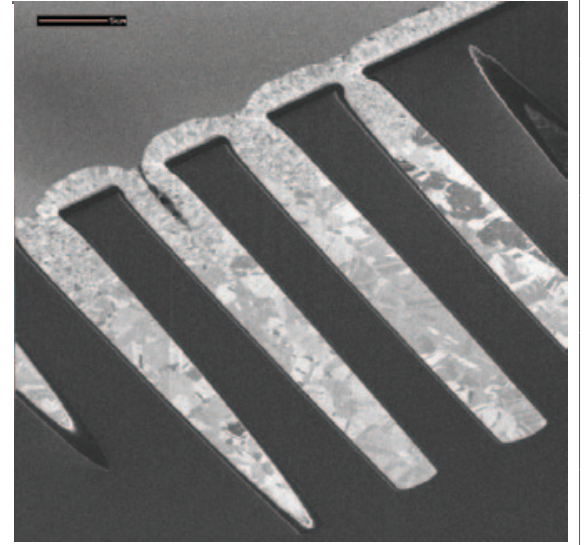

Vias fabricated at IMEC while developing their fabrication process.

Plasma FIB cross-sectioned and imaged at Oregon Physics.

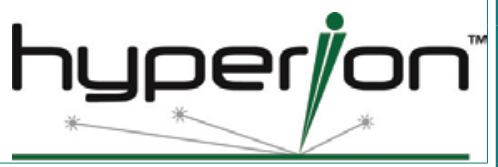

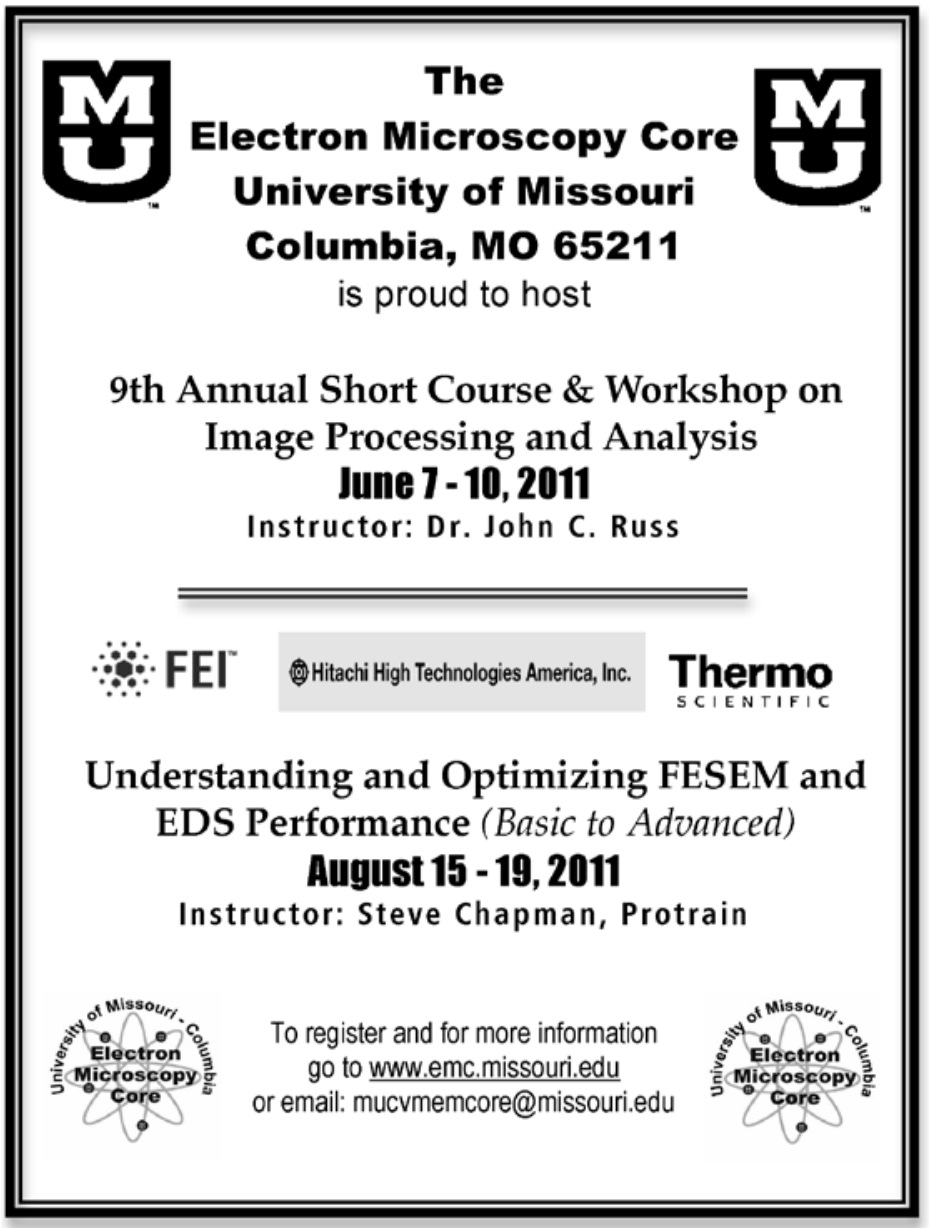

\section{The \\ University of Missouri}

is proud to host

9th Annual Short Course \& Workshop on Image Processing and Analysis June 7 - 10, 2011

Instructor: Dr. John C. Russ

$\therefore$ FEI Hitachi High Technologies America, Inc. Thermo

Understanding and Optimizing FESEM and August 15 - 19, 2011

Instructor: Steve Chapman, Protrain

register and for more information go to www.emc.missouri.edu or email: mucvmemcore@missouri.edu

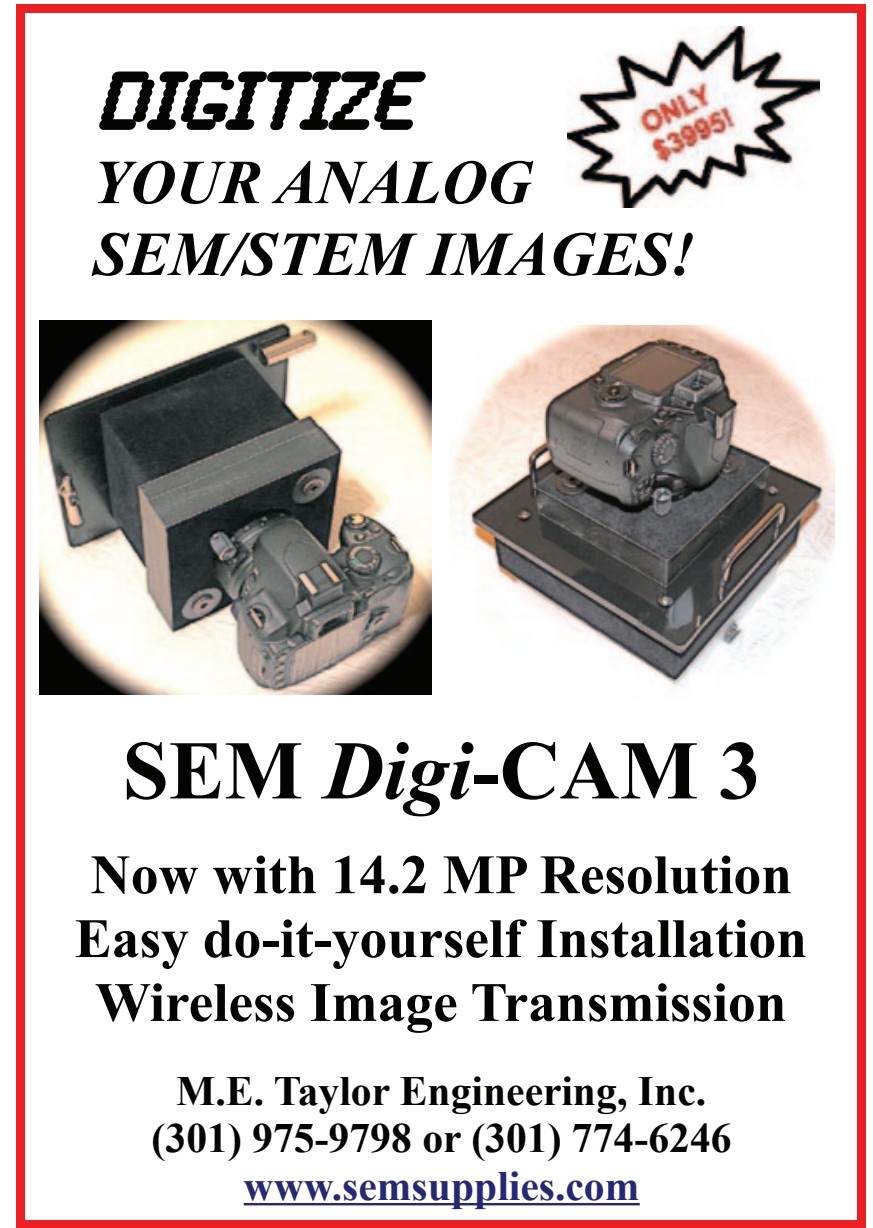

